\title{
Variation in cytochrome-c oxidase activity is not maternally inherited in the copepod Tigriopus californicus
}

\author{
SUZANNE EDMANDS* \& RONALD S. BURTON \\ Marine Biology Research Division, Scripps Institution of Oceanography, University of California, San Diego, La J olla, \\ CA 92093-0202, U.S.A.
}

\begin{abstract}
The mitochondrial enzyme cytochrome-c oxidase (COX) is composed of multiple subunits encoded within both the nuclear and mitochondrial genomes. Isofemale lines of the intertidal copepod Tigriopus californicus showed significant variation in COX activity (measured by a standard spectrophotometric method) both within and between populations. This interline variation was expressed under common culture conditions and is evidence of a genetic component to COX enzymatic activity variation. Because the catalytic core of COX (subunits I, II and III) is encoded by mitochondrial DNA, which is inherited maternally in $T$. californicus, we hypothesized that variation in COX activity may show maternal inheritance. This hypothesis was evaluated by determining COX activity among $F_{1}$ progeny of reciprocal crosses between isofemale lines. Results failed to support the hypothesis; COX activity did not show a pattern of maternal inheritance. Rather, the data suggest that genetic regulation of interline variation in $\mathrm{COX}$ activity is complex and involves nuclear genes. In general, $\mathrm{F}_{1}$ offspring tended to have higher $\mathrm{COX}$ activities than either parent, whereas $\mathrm{F}_{2}$ offspring had enzyme activities similar to or lower than the $F_{1}$, suggesting that strong nuclear-nuclear or nuclear-mitochondrial interactions affect COX function.
\end{abstract}

Keywords: copepod, cytochrome-c oxidase, enzyme activity, inheritance, nuclear-mitochondrial co-adaptation, Tigriopus californicus.

\section{Introduction}

Natural populations of organisms commonly harbour substantial variation in biochemical traits, such as enzymatic activity (Williams, 1956). The extent to which this variation reflects underlying genetic variation can be assessed either by quantitative genetic techniques yielding estimates of the heritability of specific enzyme activities (e.g. Clark, 1990) or by determining the relationship between enzyme kinetic parameters and variation at the gene loci encoding the enzyme itself (Clarke, 1975; Koehn, 1978; Place \& Powers, 1984). Although it has been shown that enzyme activities can be influenced by specific loci unlinked to the relevant structural genes (Laurie-Ahlberg et al., 1982), most studies have focused on enzymes encoded by single genes, in which the native entity consists of monomers or multimers of a single polypeptide.

*Correspondence and present address: Department of Biology, University of Oregon, Eugene, OR 97403, U.S.A. E-mail: sedmands@oregon.uoregon.edu
However, many functional enzymes are substantially more complex and consist of polypeptides derived from multiple structural genes (e.g. Attardi \& Schatz, 1988). Especially interesting in this regard are several of the enzymes involved in the mitochondrial electron transport system, which consist of polypeptide subunits encoded in both the nuclear and the mitochondrial genomes. Among these enzymes is cytochrome-c oxidase (COX); in eukaryotes, COX consists of three polypeptide subunits encoded by mtDNA genes (designated I, II and II) and numerous additional subunits (10 in mammals; Capaldi, 1996) encoded in the nuclear genome. Although the nuclear subunits may play a role in regulation or assembly of the enzyme in eukaryotes, all electron transport and proton-pumping abilities are attributed to the mitochondrial subunits (Capaldi, 1996; Tsukihara et al., 1996), and bacterial cytochrome-c oxidases composed of only the three polypeptides homologous to the mitochondrial subunits are fully functional (Wilson \& Cameron, 1994). In yeast, a single amino acid change in one of 
the mitochondrial subunits can interfere with the function of the enzyme complex (Wilson \& Cameron, 1994). Based on these observations, we hypothesized that interindividual variation in COX activity may result in part from amino acid sequence differences encoded by mtDNA. Because mtDNA is typically maternally inherited, variation in COX activity might be expected to show a pattern of maternal inheritance.

Here, we report the results of a simple test of that hypothesis. With strict maternal inheritance, reciprocal crosses between lines with different mean COX activity should yield $F_{1}$ progeny sets with different mean activities, and the difference should follow the mother. The study system consists of the intertidal copepod Tigriopus californicus, a species in which extensive mtDNA variation has already been documented. Burton \& Lee (1994) found that partial sequences $(500 \mathrm{bp})$ for the cytochrome-c oxidase subunit I (COXI) gene showed as much as $20 \%$ divergence among central and southern California populations. Although most of that variation consisted of silent substitutions, several amino acid substitutions were inferred from the DNA sequences; three amino acid differences distinguished all the central California sequences from all southern California sequences. Because it has maternally inherited mitochondria (Lee, 1993), can be readily mated and cultured in the laboratory and was known to have genetic variation in at least one of the relevant COX genes, the T. californicus system presented an opportunity to test for the maternal inheritance of COX activity variation. Our results clearly reject this hypothesis.

\section{Materials and methods}

\section{Copepod cultures}

Natural populations of T. californicus were sampled from high intertidal rock pools in California, USA, and Baja California, Mexico, and maintained as mass cultures (300 or more adults) in $400 \mathrm{~mL}$ beakers. All cultures were kept at $15 \pm 2^{\circ} \mathrm{C}$ with a $12 \mathrm{~h}$ light: $12 \mathrm{~h}$ dark cycle. Isofemale lines were established by isolating single gravid females in Petri dishes $(15 \mathrm{~mm} \times 100 \mathrm{~mm})$ and inbreeding the resulting offspring, which are full-siblings, because females mate only once (Burton, 1985). Isofemale lines were inbred for up to six generations before the enzyme activity assays. COX activity was assessed in 61 isofemale lines from a total of seven geographical locations (Fig. 1). Pairs of isofemale lines, including some pairs with substantially different COX activity

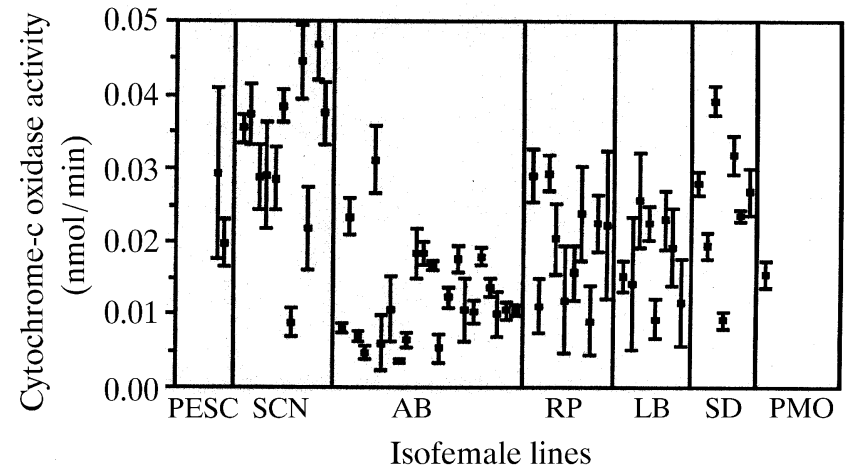

Fig. 1 Cytochrome-c oxidase activity (adjusted for total protein content, gender and sample $\times$ plate interaction) for isofemale lines from seven geographical locations listed from north to south (PESC, Pescadero Beach, San Mateo Co., CA; SCN, Santa Cruz, Santa Cruz Co., CA; AB, Abalone Cove, Los Angeles Co., CA; RP, Royal Palms, Los Angeles Co., CA; LB, Laguna Beach, Orange Co., CA; SD, San Diego, San Diego Co., CA; PMO, Punta Morro, Baja California; see maps in Burton, 1990b; Ganz \& Burton, 1995). Each point represents the mean enzyme activity ( \pm SE) for multiple copepods (mean sample size 5.9, range 3-33) from a single isofemale line.

levels, were then chosen for matings. Reciprocal interline crosses were carried out according to the methods in Burton \& Feldman (1981), using at least five virgin females from each isofemale line. When clasped $F_{1}$ pairs formed, the males and females were dissected apart and reunited in a new dish for production of the $\mathrm{F}_{2}$ generation in order to randomize matings.

\section{COX activity assays}

Activity of cytochrome-c oxidase (EC 1.9.3.1) was measured by a standard spectrophotometric assay based on the oxidation of cytochrome-c (Simon \& Robin, 1971). A solution of cytochrome-c (type VI from horse heart; Sigma Chemical Co.) and phosphate buffer (50 mм $\left.\mathrm{NaH}_{2} \mathrm{PO}_{4}, \mathrm{pH} 7.1\right)$ was reduced with ascorbic acid. The ascorbic acid was then removed by dialysis (Slide-A-Lyser cassette, Pierce Chemical Co., Rockford, IL, U.S.A.) against phosphate buffer $\left(10^{\circ} \mathrm{C}\right.$, overnight, three changes of buffer). The reduced cytochrome-c was frozen at $-20^{\circ} \mathrm{C}$ and used within 2 weeks. Adult copepods were sexed (three categories: male, female and female with egg sac) and rinsed in filtered sea water. Individual copepods were then homogenized in microcentrifuge tubes in $200 \mu \mathrm{L}$ of ice-cold homoge- 
nization buffer [freshly mixed phosphate buffer and $0.05 \%$ Tween 80 detergent (polyoxyethylene20-sorbitan monooleate; Fisher Scientific)] for approximately $10 \mathrm{~s}$ using a motorized Delrin plastic pestle fitted to $1.5 \mathrm{~mL}$ microcentrifuge tubes. After centrifugation for $5 \mathrm{~min}$ at $2000 \mathrm{~g}$, two $40 \mu \mathrm{L}$ aliquots of the supernatant were distributed into each of two 96-well microtitre plates - one plate was then used for the COX assay and the other was used for the total protein assay. For the COX assays, $160 \mu \mathrm{L}$ of $51 \mu \mathrm{M}$ reduced cytochrome-c (calculated using the millimolar extinction coefficient of 29.5 at $550 \mathrm{~nm}$ ) was added to each well, and $\mathrm{OD}_{550}$ was measured using a microtitre plate reader (UVmax; Molecular Devices Corporation, Menlo Park, CA, U.S.A.). Plates were incubated at $23 \pm 1^{\circ} \mathrm{C}$ for $30 \mathrm{~min}$ and $\mathrm{OD}_{550}$ was remeasured. The duration of the endpoint assay and the concentrations of homogenate and substrate were chosen to yield linear changes in absorption over time. For the total protein assays, $160 \mu \mathrm{L}$ of bicinchoninic acid reagent (BCA; Pierce Chemical Co.; Smith et al., 1985) was added to each well. Plates were incubated overnight at $37^{\circ} \mathrm{C}$ and $\mathrm{OD}_{562}$ was measured. Protein content was determined from comparisons with bovine serum albumin standards run on each plate.

\section{Statistical analyses}

Although enzyme activities are often reported on a per unit protein basis, this assumes implicitly that a doubling in protein content results in a doubling in enzyme activity. Instead, we used analysis of covariance (superanova, Abacus Concepts, Berkeley, CA, U.S.A) to adjust for protein content of individual copepods. Analysis of covariance was also used to factor out the effects of gender and microtitre plate. Cytochrome oxidase activity was the dependent variable, sample type (i.e. isofemale line 1 or line $1 \times$ line $2 \mathrm{~F}_{1}$ hybrid or line $1 \times$ line $2 \mathrm{~F}_{2}$ hybrid, etc.) was the main effect, and the covariates were gender, protein content and the interaction between sample and microtitre plate number. After ANCOVA adjustments, STATVIEW SE (Abacus Concepts) was used for simple regressions of offspring COX activity on parent COX activity (dam, sire and midparent) and for $t$-tests to compare COX activity in various groups.

\section{Results}

The relationship between sample and COX activity was tested by analysis of covariance. Out of 13 analyses (one for all isofemale lines and one for each of 12 reciprocal crosses), protein content had a significant effect in all but four cases, gender had a significant effect in only one case and the interaction between sample type and microtitre plate was never significant.

COX activity in 61 isofemale lines raised in a common garden varied significantly both within and among populations (Fig. 1). Many lines were assayed on multiple days, and the enzyme activity measurements were repeatable. Within populations, COX activity varied by up to fivefold (0.009$0.047 \mathrm{nmol} \mathrm{min}{ }^{-1}$ at Santa Cruz), whereas among populations COX activity varied by more than

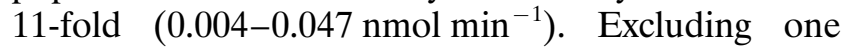
population for which only one isofemale line was assayed (Punta Morro), $48.9 \%$ of the variance was between populations $(P=0.001)$. Although some patterns are apparent (COX activity is highest in Santa Cruz and lowest in Abalone Cove), there is no geographical cline. For populations in which two or more lines were assayed, the mean is exactly the same $\left(0.025 \mathrm{nmol} \mathrm{min}{ }^{-1}\right)$ in the northernmost population (PESC) and in the southernmost population (SD).

Reciprocal crosses show little evidence of maternal inheritance (Fig. 2a-1). In some cases, enzyme activity levels are significantly different in parental lines but similar in reciprocal $F_{1}$ hybrids (crosses a, $\mathrm{g}, \mathrm{h}, \mathrm{k}$ and $\mathrm{l}$ ). In the two cases in which parental lines differ and reciprocal $F_{1} s$ differ, one cross follows the maternal line (d) and one follows the paternal line (i). Finally, in some cases, parental lines are similar, but reciprocal $F_{1}$ hybrids are significantly different from each other (crosses c, e and f).

Regressing $\mathrm{F}_{1}$ offspring COX activity on parental COX activity also provides no support for maternal inheritance (Table 1). For the six intrapopulation crosses (three reciprocals, Fig. 2a-c), $F_{1}$ offspring showed more similarity to their paternal parent $\left(r^{2}=0.19\right)$ than their maternal parent $\left(r^{2}=0.07\right)$, but neither regression was significant. For the 20 interpopulation crosses (10 reciprocals, Fig. 2d-1), $\mathrm{F}_{1}$ offspring showed very weak relationships to both the maternal parent $\left(r^{2}=0.05\right)$ and the paternal parent $\left(r^{2}=0.01\right)$, and neither regression was significant.

Overall, the six intrapopulation crosses showed a strong increase in enzyme activity in the $F_{1}$, and a small but insignificant drop in activity in the $F_{2}$ (Fig. 3a). Averaging over the seven interpopulation crosses in which both $F_{1}$ and $F_{2}$ assays were carried out reveals a weaker increase in the $F_{1}$ and a stronger decrease in the $\mathrm{F}_{2}$ (Fig. 3b).

(C) The Genetical Society of Great Britain, Heredity, 80, 668-674. 


\section{Discussion}

The hypothesis that genetic variation in $\mathrm{COX}$ activity might be maternally inherited in T. californicus derives from the observations that the three mtDNA-encoded COX subunits comprise the catalytic core of the enzyme (Capaldi, 1996; Tsukihara et al., 1996) and that mtDNA is maternally inherited in this species (Lee, 1993). High levels of nucleotide sequence variation among natural populations of $T$. californicus have been found in a fragment of the COX subunit I gene (mtDNA) (Burton \& Lee, 1994). This variation encodes several amino acid substitutions, including three that are diagnostic for
Fig. 2 Cytochrome-c oxidase activity (adjusted for total protein content, gender and sample $\times$ plate interaction) in reciprocal crosses between pairs of isofemale lines

(line 1 and line 2). Three crosses are within a population

(a, AB503 × AB507; b,

AB503 × AB510; c, AB506 × AB508) and nine crosses are between populations $(\mathrm{d}, \mathrm{AB} 206 \times \mathrm{LB} 101$; e, AB507 $\times$ PESC7; f, AB201 × LB106; g, AB506 $\times$ LB101; h, AB508 $\times$ PMO503; i, LB105 $\times$ SD419; j, LB108 $\times$ RP106; k, RP101 $\times$ SCN217; 1 ,

AB203 $\times$ SCN203). Each point represents the mean enzyme activity $( \pm \mathrm{SE})$ for multiple copepods (mean sample size 8.5 , range $3-33$ ). ND, no data.

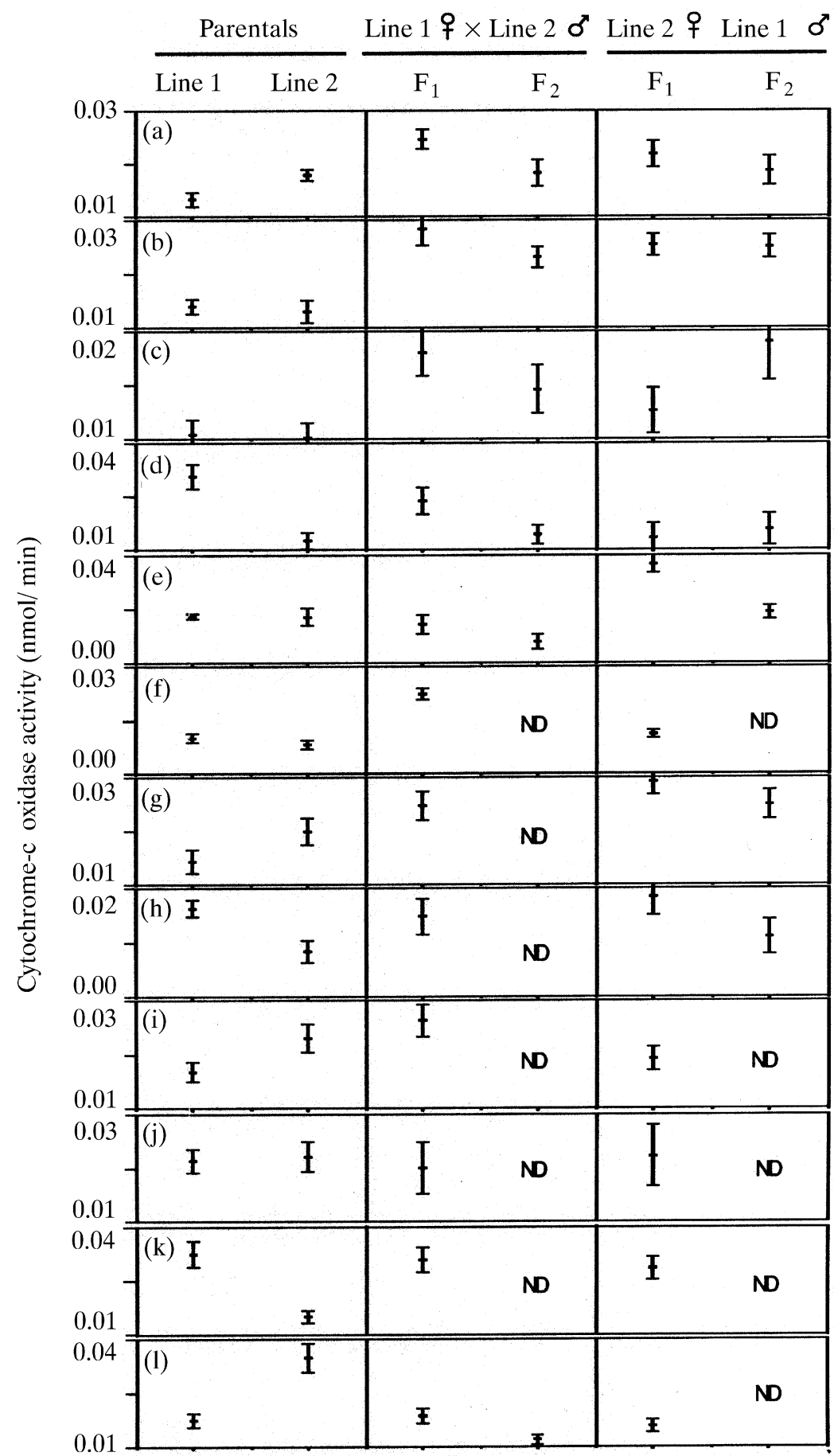


Table 1 Results of simple regressions of cytochrome-c oxidase activity in $F_{1}$ offspring on cytochrome-c oxidase activity in parental lines [maternal line, paternal line and mean of maternal and paternal lines (midparent)]

\begin{tabular}{lcccc}
\hline Comparison & $\begin{array}{l}\text { No. of } \\
\text { crosses }\end{array}$ & $\begin{array}{l}\text { Slope } \\
\text { of line }\end{array}$ & $r^{2}$ & $P$ \\
\hline $\begin{array}{l}\text { Intrapopulation crosses } \\
\text { F }_{1} \text { vs. maternal line }\end{array}$ & 6 & 0.65 & 0.07 & 0.61 \\
F $_{1}$ vs. paternal line & 6 & 1.07 & 0.19 & 0.39 \\
F $_{1}$ vs. midparent & 6 & 1.70 & 0.24 & 0.33 \\
Interpopulation crosses & & & & \\
$\quad F_{1}$ vs. maternal line & 20 & 0.19 & 0.05 & 0.39 \\
F $_{1}$ vs. paternal line & 20 & 0.04 & 0.01 & 0.85 \\
F $_{1}$ vs. midparent & 20 & 0.25 & 0.04 & 0.44 \\
\hline
\end{tabular}

central vs. southern California populations. Although this work only assessed variation over approximately $30 \%$ of one of the three mtDNAencoded COX subunits, it demonstrates clearly that mtDNA sequence variation contributes to $\mathrm{COX}$ protein variation, which may, in turn, contribute to variation in enzyme activity. The results of the experiments presented here clearly reject the hypothesis of strict maternal inheritance of variation in cytochrome-c oxidase activity in T. californicus.

Heritable variation in COX activity is evidenced by the substantial variation in enzyme activity in

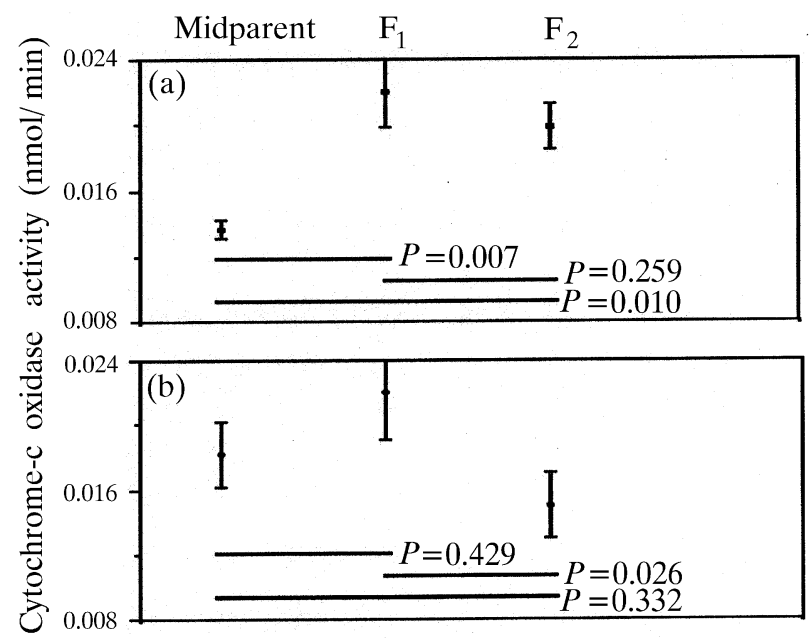

Fig. 3 Mean cytochrome-c oxidase activity $( \pm$ SE) in midparents, $F_{1}$ offspring and $F_{2}$ offspring (a) in six intrapopulation crosses and (b) in the seven interpopulation crosses in which both $\mathrm{F}_{1}$ and $\mathrm{F}_{2}$ offspring were assayed. Horizontal bars indicate which two groups are being compared, and $P$-values indicate significance of a paired, two-tailed $t$-test. isofemale lines raised under common conditions. This variation in enzyme activity does not show a geographical cline and is not clearly consistent with the geneology of the mitochondrial COXI gene (Burton \& Lee, 1994), in which the strongest differentiation was between central California (including PESC and SCN) and southern California (including $\mathrm{AB}, \mathrm{LB}$ and SD).

Despite evidence for heritability, the predicted pattern of maternal inheritance was not found. $F_{1}$ progeny from reciprocal crosses between isofemale lines differing in COX activity did not show differences attributable to the maternal line. The lack of simple maternal inheritance of COX activity suggests the involvement of nuclear genes.

The results further suggest that $\mathrm{COX}$ activity may be affected by gene interactions, either nuclearnuclear or nuclear-mitochondrial. $F_{1}$ offspring showed weak regressions to both parents in intrapopulation crosses and even weaker regressions to parents in interpopulation crosses, possibly because of more dysfunctional gene interactions in the interpopulation crosses. Comparisons of mean COX activity in parental lines, $F_{1}$ offspring and $F_{2}$ offspring also imply gene interactions. Intrapopulation crosses showed a strong increase in COX activity in the $F_{1}$ and a small and insignificant decrease in activity in the $F_{2}$. The increase in the $F_{1}$ implies a release from inbreeding depression, which is generally attributed to dominance at nuclear loci (e.g. Charlesworth \& Charlesworth, 1987). The hypothesis that inbreeding reduces COX activity is supported by measurements of enzyme activity in noninbred populations (S. Edmands and R. S. Burton, unpubl. data); it should be noted, however, that assays of the isofemale lines and noninbred populations were not run concurrently. For the population in which intrapopulation crosses were carried out $(\mathrm{AB}), \mathrm{COX}$ activity in isofemale lines (0.013 nmol $\mathrm{min}^{-1}$; SE 0.001) was significantly lower (unpaired, one-tailed $t$-test; $P=0.03$ ) than in the noninbred population $\left(0.018 \mathrm{nmol} \mathrm{min}{ }^{-1}\right.$; SE 0.001$)$. Averaging over all populations in the present study (excluding PMO, in which only one isofemale line was assayed), enzyme activity in isofemale lines $\left(0.022 \mathrm{nmol} \mathrm{m^{-1 }}{ }^{-1}\right.$ SE 0.003$)$ was again lower than in noninbred populations $\left(0.027 \mathrm{nmol} \mathrm{min}{ }^{-1}\right.$; SE $0.003)$, although the difference was not significant (paired, one-tailed $t$-test; $P=0.09$ ).

In comparison with the intrapopulation crosses, interpopulation crosses had a much smaller increase in activity in the $F_{1}$. This could be attributed to the detrimental effects of cross-breeding opposing the beneficial effects of inbreeding release. Alterna- 
tively, it should be noted that parental lines in the intrapopulation crosses (all from the $\mathrm{AB}$ population) had particularly low COX activity levels. If these low enzyme activities were caused by inbreeding, then these crosses would have experienced a stronger release from inbreeding depression.

Interpopulation crosses showed a much larger drop in $F_{2}$ activity than intrapopulation crosses. This strong $F_{2}$ decline is similar to the pattern found in interpopulation hybrids in this species for other physiological variables (response to osmotic stress, Burton, 1990a; development time, Burton, 1990b) and implies epistatic interactions between loci. Although there is previous evidence for strong nuclear-nuclear epistatic interaction in $T$. californicus (Burton, 1987), nuclear-mitochondrial interactions could also contribute to the observed COX activity patterns in interpopulation hybrids. If only a haploid complement of nonforeign nuclear DNA is necessary for normal nuclear-mitochondrial interaction, as was suggested in a study of cytochrome oxidase function by Liepens \& Hennen (1977), then nuclear-mitochondrial conflict will not be manifested until the $F_{2}$ generation. To distinguish between nuclear-nuclear interactions and nuclearmitochondrial interactions, we have carried out a series of crosses (S. Edmands \& R. S. Burton, in prep.), in which $F_{1}$ hybrids are repeatedly backcrossed to parental lines. Preliminary results indicate that some crosses show changes over time consistent with nuclear-nuclear interactions, whereas others show changes consistent with nuclear-mitochondrial interactions.

COX activity standardized to total protein, as measured here, is a function of both the amount and the activity of the enzyme. The variation in activity observed may, therefore, be caused by a variety of factors involving either nuclear or mitochondrial genes, including mitochondria number, transcription rate, transcript processing, message stability, translation efficiency, protein stability or intrinsic catalytic efficiency (Clark \& Wang, 1994).

The exact role of nuclear genes in cytochrome-c oxidase activity remains to be identified. Structural data do not indicate that nuclear-encoded subunits are involved directly in either electron transfer or proton pumping (Capaldi, 1996). Instead, they may play a role in regulating enzyme activity. The evidence suggests that nuclear subunits contain binding sites for effectors of enzyme activity (Taanman et al., 1994; Tsukihara et al., 1996). The possible effect of nuclear subunits on enzyme activity is demonstrated further by the existence of different isoforms in different tissues, which may scale enzyme activity to the metabolic needs of each tissue (Yanamura et al., 1988). Nuclear subunit IV has been implicated specifically in the regulation of COX activity, but the mechanism is not known (Liu \& Wong-Riley, 1995). Nuclear subunits may also be involved in the biogenesis of the enzyme complex, possibly by acting as 'scaffolds' or by playing a role in the folding of mitochondrial subunits (Capaldi, 1990). They may also play a role in controlling synthesis of the enzyme via transcription or translation or simply by being the limiting reagent. Control of synthesis is evidenced by the finding of different forms of subunit $\mathrm{V}$ in aerobically grown cells (high enzyme levels) vs. anaerobically grown cells (low enzyme levels) (Trueblood et al., 1988). Nuclear subunits may also stabilize the core enzyme complex and may regulate its rate of degradation as they themselves degrade (Capaldi, 1996). In addition to the nuclear subunits, studies of yeast have shown a number of other nuclear genes to be necessary for COXI expression because of their roles in transcription and RNA processing (Pel et al., 1992).

Understanding the complexities of the evolution of the mitochondrial genome requires a basic understanding of the functional interactions of mitochondrial genes with the nuclear genome. Although simplistic, our hypothesis of maternal inheritance of COX activity variation follows from the known function of the mtDNA-encoded COX subunits and the knowledge of structural gene variation in COXI in $T$. californicus. The failure of the hypothesis to account for COX activity variation indicates that even relatively simple features of mitochondrial function (i.e. the activity of single enzymes in the mitochondrial electron transport chain) are likely to be governed by complex patterns of inheritance.

\section{Acknow ledgements}

We thank C. Funk for his pioneering work on the COX enzyme assay and D. Guay for technical assistance. Thanks also to J. Blanchard and P. Rawson for comments on the manuscript. This study was supported by NSF grants DEB94-09066 and OCE94-15669 to R.S.B.

\section{References}

ATTARDI, G. AND SCHATZ, G. 1988. Biogenesis of mitochondria. Ann. Rev. Cell Biol., 4, 289-333.

BURton, R. S. 1985. Mating system of the intertidal copepod Tigriopus californicus. Mar. Biol., 86, 247-252.

BURTON, R. s. 1987. Differentiation and integration of the genome in populations of the marine copepod Tigriopus californicus. Evolution, 41, 504-513. 
BURTON, R. S. 1990a. Hybrid breakdown in physiological response: a mechanistic approach. Evolution, 44, 1806-1813.

BURTON, R. s. 1990b. Hybrid breakdown in developmental time in the copepod Tigriopus californicus. Evolution, 44, 1814-1822.

BURTON, R. S. AND FELDMAN, M. w. 1981. Population genetics of Tigriopus californicus. II. Differentiation among neighboring populations. Evolution, 35, 1192-1205.

BURTON, R. S. AND LEE, B.-N. 1994. Nuclear and mitochondrial gene genealogies and allozyme polymorphism across a major phylogeographic break in the copepod Tigriopus californicus. Proc. Natl. Acad. Sci. U.S.A., 91, 5197-5201.

CAPALDI, R. A. 1990. Structure and function of cytochrome c oxidase. Ann. Rev. Biochem., 59, 569-596.

CAPALDI, R. A. 1996. The complexity of a respiratory complex. Nature Struct. Biol., 3, 570-574.

CHARLESWORTH, B. AND CHARLESWORTH, D. 1987. Inbreeding depression and its evolutionary consequences. Ann. Rev. Ecol. Syst., 18, 237-268.

CLARK, A. G. 1990. Genetic components of variation in energy storage in Drosophila melanogaster. Evolution, 44, 637-650.

CLARK, A. G. AND WANG, L. 1994. Comparative evolutionary analysis of metabolism in nine Drosophila species. Evolution, 48, 1230-1243.

CLARKE, B. 1975. The contribution of ecological genetics to evolutionary theory: detecting the direct effects of natural selection on particular polymorphic loci. Genetics, 79s, 101-113.

GANZ, H. H. AND BURTON, R. s. 1995. Genetic differentiation and reproductive incompatibility among Baja California populations of the copepod Tigriopus californicus. Mar. Biol., 123, 821-828.

KOEHN, R. K. 1978. Physiology and biochemistry of enzyme variation: the interface of ecology and population genetics. In: Brussard, P. (ed.) Ecological Genetics: The Interface, pp. 51-72. Springer, New York.

LAURIE-AHLBERG, C. C., WILTON, A. N., CURTSINGER, J. W. AND EMIGH, T. H. 1982. Naturally occurring enzyme activity variation in Drosophila melanogaster. I. Sources of variation for 23 enzymes. Genetics, 102, 191-206.

LEE, B.-N. 1993. Genetic Structure of Tigriopus californicus Populations Inferred from Mitochondrial Cytochrome
Oxidase I DNA Sequences. PhD Dissertation, University of Houston.

LIEPENS, A. AND HENNEN, s. 1977. Cytochrome oxidase deficiency during development of amphibian nucleocytoplasmic hybrids. Dev. Biol., 57, 284-292.

LIU, S. AND WONG-RILEY, M. 1995. Disproportionate regulation of nuclear- and mitochondrial-encoded cytochrome oxidase subunit proteins by functional activity in neurons. Neuroscience, 67, 197-210.

Pel, H. J., TZAGOlOFF, A. AND GRIVell, L. A. 1992. The identification of 18 nuclear genes required for the expression of the yeast mitochondrial gene encoding cytochrome $c$ oxidase subunit 1. Curr. Genet., 21, 139-146.

PLACE, A. AND POWERS, D. A. 1984. Kinetic characterization of the lactate dehydrogenase (LDH- $\left.\mathrm{B}_{4}\right)$, allozymes of Fundulus heteroclitus.J. Biol. Chem., 259, 1309-1318.

SIMON, L. M. AND ROBIN, E. D. 1971. Relationship of cytochrome oxidase activity to vertebrate total and organ oxygen consumption. Int. J. Biochem., 2, 569-573.

SMITH, P. K., KROHN, R. I., HERMANSON, G. T., MALLIA, A. K., GARTNER, F. H., PROVENZANO, M. D. ET AL. 1985. Measurement of protein using bicinchoninic acid. Analyt. Biochem., 150, 76-85.

TAANMAN, J.-W., TURINA, P. AND CAPALDI, R. A. 1994. Regulation of cytochrome $c$ oxidase by interaction of ATP at two binding sites, one on subunit VIa. Biochemistry, 33, 11833-11841.

TRUEBLOOD, C. E., WRIGHT, R. M. AND POYTON, R. O. 1988. Differential regulation of the two genes encoding Saccharomyces cerevisiae cytochrome $c$ oxidase subunit $\mathrm{V}$ by Heme and the HAP2 and REO1 genes. Mol. Cell. Biol., 8, 4537-4540.

TSUKIHARA, T., AOYAMA, H., YAMASHiTA, E., TOMIZAKI, T., yAMAgUCHI, H., ShinZAWA-ITOH, K. ET $A L$. 1996. The whole structure of the 13-subunit oxidized cytochrome c oxidase at $2.8 \AA$. Science, 272, 1136-1144.

WILliAms, R. J. 1956. Biochemical Individuality; the Basis for the Genetrophic Concept. Wiley, New York.

WILSON, T. M. AND CAMERON, V. 1994. Replacement of a conserved glycine residue in subunit II of cytochrome $c$ oxidase interferes with protein function. Curr. Genet., 25, 233-238.

YANAMURA, W., ZHANG, Y.-Z., TAKAMIYA, S. AND CAPALDI, R. A. 1988. Tissue-specific difference between heart and liver cytochrome $c$ oxidase. Biochemistry, 27, 4909-4914. 